\section{Sin encrucijada en el alma}

\section{Without "crossroads of soul"}

\section{Paulo Emilio Archila • Bogotá D.C.}

Una extraña sensación se percibe al escribir un editorial como Editor Emérito de Acta Médica Colombiana, revista que he amado como asiduo lector internista desde que era residente, y por la cual trabajé con intensidad y máximo interés durante los 11 años que tuve el honor de ser su Editor General. No hubo "encrucijada del alma" para decidir mi renuncia, simplemente encontré que era suficiente tiempo y hora de permitir que otros tuvieran la oportunidad de seguir la tarea.

La Junta Directiva de la ACMI me honró una vez más al nombrarme Editor Emérito y a la vez me comprometió a permanecer activo en la toma de decisiones, colaborar en el diseño de la política editorial y aportar toda la experiencia adquirida al nuevo Editor General. Ésto me compromete aun más con la Revista, dejando tiempo disponible para otras actividades diferentes a las arduas jornadas de evaluación, diseño, corrección, financiación y los tediosos procesos de indización.

La Junta Directiva tuvo el acierto de seleccionar el nuevo Editor entre los Editores Asociados, ya que todos tienen los merecimientos y la experiencia necesaria para la importante misión. El nombre del elegido no es desconocido para Acta Médica, pues el doctor Eugenio Matijasevic ha trabajado en ella desde hace más de 20 años, al lado de los fundadores y primeros editores, doctores Fernando Chalem y Jorge Escandón. Eugenio es un experto en la normatividad de las publicaciones científicas y conoce perfectamente los delineamientos de Colciencias, Scielo y la NLM (National Library of Medicine), además de su experiencia en el análisis crítico de artículos biomédicos y su profundo conocimiento de la Medicina Interna, la cual ejerce acertadamente en la Fundación Santa Fe de Bogotá, tiene las mejores relaciones humanas y es conocedor del ámbito científico, en el cual es ampliamente respetado.

Acta Médica Colombiana tuvo momentos de crisis provocados por los cambios en la estructura de la ACMI, sus dificultades económicas, la reducción del apoyo de los anunciadores y el atraso en los procesos de indización, el cual redujo notoriamente el número de trabajos sometidos a consideración para publicación en nuestras páginas, siendo atraídos los investigadores por revistas con mayor puntaje e incluidas en mayor cantidad de bases de datos bibliográficas, por lo tanto con mayor factor de impacto.

Nuestra primera meta fue modernizar la publicación, tanto en su diagramación escrita y electrónica como en las normas editoriales, siguiendo las pautas del Publindex (Colciencias) para lograr puntajes más altos y poder acceder a las bases de datos internacionales, como Lilacs (Índice Latinoamericano), Scielo (Scientific electronic library on-line), con texto completo y resúmenes en inglés, y posteriormente el ingreso a A.B.R.Thomson y a Redalyc ( Red Latinoamericana y del Caribe) que está actualmente en estudio para su inclusión, toda vez que nos invitaron a hacer parte de esa conocida red originada en México por cumplir los
Dr. Paulo Emilio Archila Falla: Editor Emérito Acta Médica Colombiana. Especialista en Medicina Interna y Gastroenterología Clínica del Country. Bogotá, D.C. e-mail: paulo.archila@gmail.com Recibido: 10/III/10 Aceptado: 10/III/10 
requisitos para su admisión. Para ello hemos debido modificar la estructura administrativa y científica de la revista y adoptar variados sistemas de marcación de los artículos para su ingreso a las bases de datos. Lamentablemente no están unificados internacionalmente y nos obliga a duplicar el trabajo de marcación con asesores externos entrenados para el efecto. Nuestra Asistente Editorial, Clara Ramírez estaba siendo entrenada para estos menesteres, pero al ser trasladada por las directivas de la ACMI al cargo adicional de Asistente Administrativa de la Asociación, no le alcanzó el tiempo para ambos oficios.

Una innovación importantísima fue la adopción del sistema de evaluación ciega por pares de todos los trabajos científicos. La colaboración desinteresada de los pares académicos ha sido fundamental para el desarrollo de la publicación, y tanto ellos como nosotros hemos aprendido mucho con este nuevo sistema. Los autores han respetado sus indicaciones y han aprendido a perfeccionar sus trabajos. Es la función educativa de una revista como la nuestra.

La labor del Editor Asistente y del Corrector Médico, ha sido muy benéfica para evitar el fenómeno de plagio y de referencia bibliográfica errada.

El ascenso en los puntajes de indización, con mejoría del factor de impacto catapultó a la revista nuevamente, con aumento significativo de los trabajos para publicación, con mejor calidad al seguir con esmero las indicaciones a los autores rediseñadas y mayor exigencia en el cumplimiento de las normas de epidemiología clínica. Ésto hizo la revista más atractiva para los anunciadores, mejorando la pauta publicitaria y el consecuente financiamiento de la publicación.

Actualmente cuenta con el apoyo completo de la Tesorería de la ACMI, al haberse integrado totalmente al esquema financiero de la Asociación, el cual ha sido francamente exitoso.

El papel de los Editores Asociados, del Comité Editorial y del Comité Científico siempre fue proactivo y fundamental para todas las etapas de reestructuración y modernización de la revista, y nos demuestra que la existencia y progreso de una publicación médica durante 35 años no es producto del trabajo de una sola persona, sino de un equipo humano y técnico de tan alta calidad como el nuestro. La labor del Editor General es la de armonizar y dirigir todo el proceso editorial, desde la búsqueda de artículos, su selección, su correcta edición, la financiación y hasta la comunicación hacia la comunidad científica por todos los medios que la nueva tecnología de difusión del conocimiento tiene a nuestra disposición; desde la página impresa para lectura local, hasta el internet en nuestra página web y en las redes internacionales para la difusión universal, manteniendo relaciones amistosas y de cooperación con todos quienes nos dedicamos a las publicaciones científicas. En esta parte es necesario destacar la colaboración de la Federación Panamericana de Facultades de Medicina al comienzo, la Organización Panamericana de la Salud, Colciencias, Bireme en Brasil, el grupo Scielo-Colombia y sus coordinadores en la Universidad Nacional de Colombia, así como los editores de todas las revistas científicas colombianas, con quienes trabajamos en armonía y adoptando políticas conjuntas para el desarrollo de la comunicación científica nacional.

Después de agradecer a todos mis colaboradores en Acta Médica Colombiana, ACMI, y a los autores y lectores por su permanente apoyo en mi gestión, me resta desearle al Dr. Matijasevic y a su equipo editorial, el mayor de los éxitos en la fructífera labor de ser el comunicador de los internistas de Colombia. 